\title{
A Pragmatic/Structural Approach to Relevance
}

\author{
Michael P. Jordan \\ Queen's University
}

Les auteurs de manuels portant sur la rhétorique, la rédaction technique et la communication commerciale sont tous vraisemblablement très conscients del'importance de n'inclure, dans un document, que l'information pertinente, celle qui correspond aux besoins des lecteurs et à la finalité du document. Néanmoins, sur 83 manuels de ce type que nous avons récemment consultés, seulement trois mentionnent la pertinence dans leur index des sujets et seulement deux d'entre eux présentent des conseils utiles à ce propos. Il semble que nous sachions peu de choses sur cette question (ou que nous $y$ attachions peu d'importance), même si on en parle abondamment depuis quinze ans dans les sciences cognitives. La brève analyse qui suit vise à faire prendre conscience de l'importance de ce concept et présente les principaux paramètres d'une théorie générale de la pertinence dans les documents fonctionnels.

\section{Background}

In their account of "Relevance Theory," Sperber and Wilson $(1982,1986,1987)$ define relevance as:

Other things being equal, the greater the effort involved in the processing of a given piece of information, the smaller its relevance to the individual who processes it. (1986, p. 40)

This approach relies on the cognitive skills of individual listeners and speakers of the language, and it ignores the possibility of defining relevance in terms of how well any particular statement contributes to, or fits in with, the remainder of the text. More importantly, it ignores the wider concepts of the document's communicative purpose and the needs of readers. Their a-contextual approach is criticized by Mey and Talbot (1988, p. 747), who point out that Sperber and Wilson: 
... exclude language from communication; or rather they establish language as non-communicative.

Considerable scholarly effort has been expended in seeking to justify and refine the principles of relevance theory as:

... an important psychological property - a property of mental process which the ordinary notion of relevance approximates. (Sperber and Wilson, 1986, p. 119)

This work, however, has done little to help us understand the "real" meaning of relevance in actual language use - and perhaps has deterred us from seeking to understand what relevance really means in technical communications. Cognitive scientists have, in effect, hijacked the term relevance for their own special purpose, and language scholars have perhaps been reluctant to seek more practical definitions of relevance in actual language use.

As a discipline that is vitally concerned with what is included in a document or presentation (as well as how it is presented), professional communication needs to establish its own theory of relevance. This present paper seeks to remedy the current deficiency. It uses documented criticisms of relevance theory in an effort to define the major elements of relevance as a useful concept in understanding the most relevant contents of practical communications.

\section{Relevance to Purpose}

In a recent critique of relevance theory, Jordan (1998a) discusses many instances in which the theory is inconsistent with examples of actual language use. He explains how Ranous, one of the early writers of technical-writing texts, discusses the effects of audience and purpose on the information presented in a document. Ranous (1964, pp. 9-21) shows how the contents of documents describing the same instrument or machine would be significantly different when written for five engineering audiences: non-technical management, fellow specialists, fabrication technicians, maintenance technicians, and operators and users. The information available to the writer is the same, but the information selected for inclusion in each document would be determined by its relevance to the needs of readers. The differences would be even greater, of course, if readers were senior management, potential buyers, sales-promotion personnel, accountants, and so on. This approach is supported by Wilks (1986) and Clark (1987a), who both express the view that relevance must be with respect to some person or group, that is, for an explicit or implicit audience.

To illustrate the effect of document purpose on the relevance of material in a 
document, Jordan (1996, p. 35) points out that a description of the same person differs markedly depending on the document's purpose (e.g., for a passport, a job application, a police record, an academic advertisement, or a personal advertisement). An example is:

(1) I'LL CALL YOU BACK! 30-year-old female student $155 \mathrm{lb}, 5^{\prime} 3^{\prime \prime}$, outgoing and lovable. A smoker, n/d. Enjoy walking, dancing, swimming, dining out, country music. Seeks a male, 35-40, no children and like to have fun. (Kingston This Week, March 19, 1987, p. 10B — from Jordan, 1998a, p. 740)

The personal details provided in this classified advertisement are all relevant for the purpose of finding someone suitable as a permanent companion, but they would not be relevant in, say, a letter of application for employment. For that purpose, readers would think it very odd indeed to be provided with that sort of information. Thus relevance is not (as claimed in relevance theory) a concept dependent only on the readers' cognitive abilities, but depends on the background and needs of readers and the purpose of the document, as noted in Jordan $(1984$, p. 10):

\section{The Question of Relevance}

What is relevant, of course, can now be seen as the information that achieves the purpose of the document and meets the needs of readers .... First you must decide why you are writing the report and who will read it. Only then are you able to make a meaningful decision as to what is relevant.

\section{Relevance to Topic}

In raising the contextually based question, "Relevance to What?" Clark (1987a) pointed out that relevance is not simply a matter of how well an item of information is processed by the listener or reader, as it depends on the topic of the communication at the point it is presented. Earlier, Sperber and Wilson (1982) had made a similar point about an announcement of "Fire!" during a theatre performance. Assuming there actually was a fire, this is certainly a relevant statement for the audience, yet it would not be relevant to the performance going on at the time. This is like opening and operating two or more windows of text on a computer at the same time; a statement can be relevant in one window, but not in another. This concept, earlier called layering (Goffman, 1974; Bruce, 1981; Clark, 1987b), is exemplified by Clark (1987a) in his discussion of the "play within a play" in Hamlet. Gorayska and Lindsay's (1993) later discussion of the "roots of relevance" elaborates on Clark's views regarding the need for relevance to be related to a specific topic.

Although layering is quite common in everyday informal speech, it rarely occurs 
in professional communications, which usually deal with well-defined single topics or areas of study. Exceptions are the use of sidebars in detailed technical articles, and appendices in complex technical or business reports. Usually, once the topic is identified in the title and prefatory material, any information outside that topic can be regarded as irrelevant. Problems of relevance arise when the title, declared intent, and information in the text fail to coincide, as we see in the following letter from a Grade 6 student:

(2) My letter is about world peace. To stop violence. To make the world a better place. To stop pollution.

To stop violence in the world, you shouldn't be a person who is racist. Don't be in a gang or the mafia. Don't sell drugs to people. Don't back-bite people.

To stop pollution from contaminating the air, don't use cars a lot. Don't start forest fires. Don't play with matches. The factories shouldn't pump all that carbon dioxide.

To stop polluting the water, don't throw junk in the water. Don't waste paper a lot. Don't use up all the water.

That's my way of contributing to the world. To stop pollution in the air and water for people all around the world. (Ottawa Citizen, December 22, 1998, p. C5)

The initial declared topic of this letter is world peace, and the first two paragraphs do deal with that subject. However, the subject of pollution is introduced at the end of the first paragraph, and the remainder of the text deals with pollution not world peace. As no connection is made in the text to link pollution with world peace, we have every right to regard it as irrelevant to the initially declared topic. To provide clarification, the editor had added the title "Stop Pollution" to this letter. The last three paragraphs of information are clearly relevant to that topic, but of course the first two are not. We really have here two documents interwoven into one, with each containing relevant information about the two quite separate topics.

We can see from this example that information can be made relevant by including a superordinate topic in the title and/or the declared topic of the document. The key test is whether the aims, purpose, and proposed contents stated early in the document are consistent with the actual information provided. In the following example, the topic is made clear in the title and first sentence: 
(3) Who says Canada is dull? One of the abiding myths out there in vacuumland is that Canada is the dullest place on earth. The British press dwells on it. Everybody in Washington believes it. The French in France can't believe the Quebec accent. (Maclean's, March 20, 1996, p. 80 - from Jordan 1998a, p. 724)

However, with the title and first sentence introducing the topic of Canada being dull, the final sentence here is not relevant to that topic, as it does not provide information relating to it. The second and third sentences are relevant to the stated topic as they provide different views of the topic.

\section{Some Empirical Results}

In early discussions of problem-solution patterning in technical reports, Winter (1976) used scrambled texts as the basis for asking students to place the information given into an acceptable sequence using categories of "Situation-Problem-Solution-Evaluation." An example is:

(4) In England, however, the tungsten-tipped spikes would tear the thin tarmac surfaces of our roads to pieces as soon as the protective layer of snow and ice melted. Road maintenance crews try to reduce the danger of skidding by scattering sand upon the road surface. We therefore have to settle for the method described above as the lesser of two evils. Their spikes grip the icy surface and enable the motorist to corner safely where non-spiked tyres would be disastrous. Its main drawback is that if there are fresh snowfalls the whole process has to be repeated, and if the snowfalls continue, it becomes increasingly ineffective in providing some kind of grip for the tyres. These tyres prevent most skidding and are effective in the extreme weather conditions as long as the roads are regularly cleared of loose snow. Such a measure is generally adequate for our very brief snowfalls. Whenever there is snow in England, some of the country roads may have black ice. In Norway where there may be snow and ice for nearly seven months of the year, the law requires that all cars be fitted with special steel-spiked tyres. Motorists coming suddenly upon stretches of black ice may find themselves skidding off the road. (Winter, 1976, p. 70 )

In addition, he would often include a sentence, such as "Traffic in Norway has increased by $20 \%$ over the last five years." within the jumbled mess, and then ask students to determine and delete this "irrelevant" or "least relevant" sentence in their final version. Although Winter did not document his results on the relevance issue, he did note that the exercise was useful in helping students to understand the principles 
of relevance as well as the structure and cohesion of the communication.

For a more recent writing test, at Queen's University in Ontario, Jordan (1998b) explains how, once the purpose and audience of a memo or report have been defined, information is given orally for students (a) to arrange into an appropriate sequence and then (b) to write the document. Some information irrelevant to the purpose or readers is deliberately included, and students are expected to determine the relevance of each statement and include only information that they judge to be relevant. As an example, in a memo to a department head concerning safety deficiencies in the head's building, information about her article on aircraft storm-warning devices published in Flight is included in the material presented to students (p. 70). This is irrelevant because it does not contribute to the objective of the document, which is to report findings of a safety inspection (p. 69).

This type of information was recognized as being irrelevant by most of the more successful students who took the literacy test, including some who failed the test for other reasons. However, the weakest of the failed students failed to recognize such statements as being irrelevant, and many had difficulty understanding that the material was irrelevant even after it had been explained to them during an interview. Although the theory and empirical study of relevance in professional writing is barely in its infancy, the work done so far indicates that principles of relevance are not always well understood by many students, and that we do need to explain them as part of our instruction.

\section{Irrelevance of "Known" Material}

Another form of irrelevance included in the Queen's University test involved information assumed to be known by the reader, such as the locations of certain rooms in the building. For example, as the readers of the safety memos described by Crawford (1995) and Jordan (1998b) would know that the photocopying room in their building is adjacent to the departmental office, that information should not be included. Students of all levels of writing ability were much weaker in recognizing this type of irrelevance, perhaps largely because they had had little practice writing functional documents with "real" recipients (other than their instructors) under "real" circumstances. This is a common relevance error for even accomplished student writers. As most worthwhile writing exercises have defined readers and purposes, we should insist that students exclude information already known by the readers except as brief reminders as the basis for additional related information (see Jordan, 1990).

The recognition and use of given and new information to readers leans on the early work of the Prague School structuralists (e.g., Daneš, 1974; Firbas, 1974), who 
were principally concerned with the structure and order of information within the sentence. This distinction of information type, which has been used extensively as the basis for work on Theme and Rheme within Systemic-Functional Grammar, is defined by Chafe $(1974$, p. 111) as:

... this distinction [between new and old information] is based precisely on a speaker's assumption as to what is in the addressee's consciousness at the time of speech.

and extended into the concept of known by Dahl (1976, p. 47):

The criterion is whether some piece of knowledge is assumed by the speaker to be known by the addressee or not.

The broader definition by Dahl is more suitable as the basis for relevance, as we should be concerned with information that is known but not necessarily at the forefront of the addressee's mind. The earlier taxonomy of given and new (e.g., Clark and Haviland, 1977; Prince, 1981) is not entirely suitable for studies of relevance, as given refers to information presented earlier in the text. If readers already know something (whether from previous knowledge, or because it has been given earlier in the text), we should regard that item of information as irrelevant to the needs of readers and the purpose of the document; it should therefore be excluded. This applies at all levels of the document, for example:

(a) In introductions to large documents, paragraphs of known information about the topic to be discussed can often be excluded.

(b) In shorter documents, sentences of known information are often unnecessary (see above discussion of Winter, 1976 and the Queen's Test of Written English).

(c) Full forms of acronyms should not be included when readers already know what the acronym means (e.g., RCMP for Canadians; OSAP for Ontario students).

(d) Obvious (known) links between statements should be omitted.

An example of the last of these appears in part of a conversation cited by Eggins 
and Slade (1997, p. 14):

(5) Bill: She ha ha she said. "You've got a decent old scar there" ... I said "Oh yeah." [laughing slightly] I said "I'm not gonna show you where it ends!"

Mavis: $\mathrm{Mmmm}$

All: [laughter]

Bill: $\quad$ And she said "Why?" I said "It goes a fair way down!" [laughs]

Bill and Mavis were obviously not intimately involved with one another, and the link between Bill's decision not to show Mavis where his scar ends and the reason given was clearly known to, and understood by, Mavis at the time; it was therefore excluded. This is the sort of unstated or inexplicit knowledge discussed in connection with the given-new contract by Clark and Haviland (1977). Riley (1993) and Parker and Riley (1994) make such links (or "bridges") explicit in examples where the two statements are less obviously connected. In some cases, the known information can be made explicit through a detailed analysis in terms of syllogisms and soriteses (e.g., Govier 1987, pp. 81-104; Walton 1996, pp. 220-55).

\section{Relevance to Unfolding Discourse}

Both Dascal (1977) and van Dijk (1980) felt that earlier views of relevance (e.g., Grice's [1975] communication cooperation principle of "relation," or connection with earlier text) are too narrow. Sanders $(1980,1987)$ expanded the definition by stating that:

... the relevance of an utterance [is] a product of its contribution to the coherence and progress of the unfolding discourse or dialogue. (1987, p. 82)

Thus, for Sanders, there are two necessary criteria for relevance: the earlier definition of textual connection, and contribution to the continuing discussion. He noted that text that is clearly connected lexically to earlier text might nevertheless be irrelevant to that earlier text, using the example:

(6) S: John needs cheering up; he flunked his exam.

H: $\quad$ Fred saw John at dinner last week. (Sanders, 1987, p. 82)

That is, Sanders regards a relevant statement as necessarily contributing both to the 
coherence of the text and also to its "progressing towards a [satisfactory] resolution" (Edmondson, 1981) of a document or interchange.

Thus, in considering whether a statement is relevant or not, we need to take into account its contribution to the unfolding discourse and progression of that discourse toward a satisfactory conclusion. This means that a statement's position in the text may have important implications for its relevance, as it must contribute to the rhetorical aim of the part of the text it contributes to. Jordan (1998a, p. 743) discusses relevance to unfolding discourse with the following example:

(7) The Provincial Minister of Education announced an increase in tuition fees by $20 \%$ today. The tuition increase should not be employed at the present time.

Tuition, at post-secondary institutions, has been increasing over the past 15 years. The universities can only bear so much of the burden of a debt-ridden government. Most university students will not be able to afford this rapid increase. It is certain that the rate of increase of new OSAP [Ontario Student Assistance Programme] loans will not be able to cover the new tuition costs. Furthermore, student summer jobs will not cover the costs either. (Student writing, Queen's University, February, 1997)

In this well-structured, thesis-denial-basis extract, the role of the second paragraph is to provide basis for the denial in the second sentence. However, although sentences $1,3,4$, and 5 of paragraph 2 contribute to this goal, sentence 2 does not. The universities are not being required to bare the burden of a debt-ridden government by the tuition increase - students are!

The second sentence of paragraph 2 is an interesting assessment that could be relevant to some other argument, it is irrelevant to the unfolding discourse at this point in the text and should therefore not have been included here - in spite of the fact that it has lexical connections with the text.

\section{Degrees of Relevance}

In some instances, the text predicts the following type of information so clearly that nothing else will suffice. The following extract establishes a clear prediction:

(8) Jim Nicholson wants the officials who let his daughter's killer out of prison to be accountable for their mistake .... Nicholson is not alone is seeking compensation. (Kingston Whig Standard, February 3, 1997, p. 3 - from Jordan 1998a, p. 739)

Readers will now expect information about someone else who is also seeking 
compensation for the same reason. We are not disappointed:

(9) In January, the family of 22-year-old Isabelle Bolduc, of Sherbrooke, Qué, filed a claim after learning two of the accused were on parole when she was murdered last July. (continuation of Example 8)

Only that type of information would satisfy the readers' informational needs at that point in the text; anything else would be irrelevant.

In many instances, however, many items of information would fit in cohesively and semantically with the text and some of these items could be regarded as being more relevant than others. In an otherwise excellent discussion of the principles of relevance, Gorayska and Lindsay (1993) express the view that we cannot have degrees of relevance. Nicolle's (1995) criticism of this view is well-justified and the reply by Gorayska and Lindsay (1995) is unconvincing. Hasan (1985) also recognizes degrees of relevance. In her explanation of "tokens," she lists "relevant tokens" and a special interactive class of these, called "central tokens":

$\begin{array}{ll}\text { peripheral } & \text { tokens which do not participate in strings or chains } \\ \text { relevant } & \text { tokens which do participate in strings or chains } \\ \text { central } & \text { relevant tokens which interact. (Martin, 1992, p. 432) }\end{array}$

Although, as noted by Sanders, participation in cohesive strings and chains does not always ensure relevance, Hasan does accept the principle that some information is more relevant cohesively than others. In fact, usually at almost any point in a text, the writer can provide many different items of information - and they could all be relevant, to one degree or another, to the cohesion and topic of the document at that point. The otherwise extremely narrow definition of relevance given in Lay et al. (1995, p. 146) does recognize degrees of relevance:

Relevance refers to the appropriateness of the evidence to the case at hand. Some kinds of evidence are seen as more relevant than others in science and industry.

Relevance, of course, applies to all aspects of information, not just basis for assessments. We can identify priorities of relevance for competing items of information in the following newspaper summary:

(10) $\$ 40,000$ Load Taken From Truck by Thieves

A five-ton truck stolen from Napanee over Christmas was found north of Kingston yesterday morning - minus its load of $\$ 40,000$ in auto parts, supplies and tools. It's a major blow to a small company already reeling from 
another devastating loss this year. The truck, belonging to R\&S Lovelock Assoc., of RR6, Napanee, was last seen Christmas Day, parked in its usual spot in the Roadway Towing lot in Napanee. It turned up yesterday morning in a sand pit on McGarvey Road, off the Battersea Road in South Frontenac Township. Its interior shelves were stripped of their contents. Please see Page 3 for the story. (Kingston Whig Standard, December 29, 1998, p. 1)

The information provided in this summary is not all at the same level of importance, as I found when I asked a group of students about to start a writing course to delete the "least relevant" statement (sentence or part of a sentence) from the summary. There were 15 responses deleting the last sentence, 9 deleting the second sentence, 3 deleting the third sentence (or part of it), and 4 deleting the fourth sentence (or parts) as well as parts of the third sentence; 2 removed the adjective five-ton. This informal survey shows that, for novice writers at least, relevance is very much a matter of personal judgment. Perhaps more consistent results would be achieved from experienced writers, who have developed a real sense of what is noteworthy for a specified topic and interesting to specified readers. Perhaps not. At present, we appear to have no sound basis for deciding which information is more relevant than others.

Example 10 is a summary of the much larger article referred to at the end of the summary, and in fact is the first three paragraphs of that full account. That article contained information about the insurance held by the owner, the expected payback amount and timing, the loss by fire of another of the owner's trucks earlier in the year, and police efforts to trace the culprits. Any of this information is also relevant to the story, and some of it (e.g., insurance details) is arguably more relevant than some of the information included in the summary. In a given context, some information is clearly more relevant than others, and this perhaps should be the guiding principle for summary writing. But we have yet to determine the criteria on which such decisions of relevance should be made.

In general terms, what is relevant is often a matter of personal judgment as to which parts of the information available would be more newsworthy or interesting to readers than other parts. In this respect, Sperber and Wilson's (1986) notion of "optimum relevance" and their cline from relevant to irrelevant is useful, although perhaps most relevant would be a better choice for the top end of the scale. Gorayska and Lindsay (1993) suggest the term interestingness (see Frick, 1992) as an alternative label for the concept defined by Sperber and Wilson, but that is more useful as a term for explaining the basis for the degrees of relevance in general accounts of events, as in Example 10. There is, of course, no clear definition of interestingness. As many 
documents are not meant to be interesting as a prime aim, relevance needs to be determined by how well (or badly) the information helps to meet the principal purpose of the document (to instruct, explain, inform, persuade, etc.).

\section{Other Types of Relevance}

In technical writing, our main concern is with substantive relevance: relevance to the unfolding discourse and the purpose of the document. That has been the type of relevance discussed here so far. However, we often need to provide procedural information to help readers to find and read (or review) the material, and so we need to recognize procedural relevance as a separate "window" of information type in a document. Although explaining how material is organized within a large document is not relevant to the substantive information in the document, it is nonetheless relevant to the needs of readers and therefore also to the overall effectiveness of the document.

In discussing the discourse marker well, and so-called irrelevant repetitions, Jucker $(1994,1998)$ notes that such utterances achieve other functions in discourse (those dealing with emphasis or implied meaning), and these are further types of relevance we need to be aware of. Emphasis in technical writing can be achieved by marked forms of expression, or by the use of illustrations or tables. Although some illustrations serve the sole purpose of providing additional information, others summarize, emphasize, or clarify discussion in the text while still others are deliberately attractive - to make the document more pleasing to the eye. Such illustrations must therefore be justified, at least in part, in terms of non-substantive terms of relevance. That is, we need to recognize that there is more to an effective document than just the information it provides, and some parts of a document may be relevant to those other needs.

We also need to recognize interpersonal relevance, based on Halliday's (1970, pp. 143-4) classification of the ideational (informational), textual (cohesive and structural), and interpersonal metafunctions of language. This relates to Pike's (1982) later analogy of language with light in physics as simultaneously exhibiting qualities of particle, wave, and field. Many utterances in speech serve the interpersonal function, which is defined by Thompson (1996, p. 28) as:

... [the use of] language to interact with other people, to establish and maintain relations with them, to influence their behaviour, to express our own viewpoints on things in the world, and to elicit or change theirs.

The interpersonal function of language helps us to explain (though perhaps not entirely justify) the personal emphasis often apparent in popular journalism. 
This emphasis occurs, for example, with personal descriptions of a member of the public in newspaper reports, the focusing of the camera on a speaker's hand position or movements in TV interviews, and the irrelevant (to the news at least) personal chit-chat that often accompanies the end of TV news programs. None of these can be regarded as relevant in any substantive sense, yet they do perhaps meet some of the interpersonal needs expressed by Thompson. Many "politeness strategies" (Brown and Levinson, 1978, 1987) can also be regarded as relevant interpersonal tactics to save positive or negative face. For example, the polite opening, "I wonder if you could do something for me" provides little substantive information, yet it is often useful as a strategy to minimize the coming threat to the recipient's negative face.

In most genres of conversation between people who are familiar with each other, the "talk is NOT motivated by any clear pragmatic purpose" (Eggins and Slade, 1997, p. 19), but is motivated entirely by interpersonal needs - especially when we talk about nothing in particular. Under such circumstances, almost anything can be relevant in a substantive sense, as there is a "randomness of subject matter and a general lack of planning" (Crystal and Davy, 1969, p. 103). Difficulties can arise, however, when strangers use politeness strategies that are normally reserved to those who have already met:

(11) caller: Good evening. I'm calling from AT\&T. Could I speak to Mr. or Mrs. Jordan?

recipient: Speaking.

caller: And how are you this evening?

recipient: Is that relevant?

caller: [pause] Well it is to me. [much longer pause] Well ... how are you this evening? [recipient hangs up] (Personal conversation, December, 10, 98)

The caller was presumably following a script with the initial aim of establishing closer relations between the caller and recipient. But the recipient perceived this as irrelevant to the implied purpose of the call, which was to solicit new business for longdistance telephone services. The caller was unable to depart from his given script by providing information of substantive relevance to the recipient, and the communication failed. 


\section{Legal Relevance}

In a recent discussion of negation in context, Jordan (1998a) includes analyses of the power of negation in legal situations, showing that relevance in legal contexts has nothing to do with how easily statements are understood, as claimed by relevance theory. On the contrary, many extremely difficult statements in law are nevertheless highly relevant and thus justify a great deal of effort in interpreting them. We should regard these as involving another, special type of relevance. The question of relevance is raised as a formal objection in the following extract of a fictitious trial in the city of New York:

(12) Defence lawyer:

$\begin{array}{ll}\text { Defence lawyer: } & \begin{array}{l}\text { So you worked six days a week for three years without } \\ \text { fail? }\end{array} \\ \text { Witness: } & \text { Yes. } \\ \text { Defence lawyer: } & \text { How's your health? } \\ \text { District attorney: } & \text { Objection. Relevance, your honor. } \\ \text { Defence lawyer: } & \text { Goes to credibility, your honor } \\ \text { Judge: } & \text { I'll allow it. } \\ & \text { (Law and Order, Channel 19, January 6, 1999, 19:53 hrs) }\end{array}$

The district attorney raised the objection because he did not see how the health of the witness was relevant to the cross-examination. Barristers can only introduce information deemed relevant to the case by the judge, and the question on health appeared to have no bearing on the case. The judge accepted the claim that the health of the witness was relevant and thus allowed the defence lawyer to continue the line of questioning. The defence lawyer then demonstrated that the matter was relevant, by showing that the witness had been in hospital for a whole month with appendix complications during the period in question. This in turn showed that the witness had lied in his first statement cited here, and that went against the general credibility of the witness, in other words, he was therefore perceived to be less reliable, or honest, as a witness.

In legal situations, relevance (and, if so, its extent) is often a matter that has to be determined by a judge or jury. Is it relevant that a murder suspect disliked the victim? Or that an accused thief was heavily in debt? Or that a person convicted of assault came from a broken home? Or that an alleged rape victim had a history of rape allegations? Or that a six-year-old will return to Cuba after being reunited with his father? Many such instances depend on law rather than subjective views of fairness, on the facts of the case rather than opinions, and on actual wording rather than how it was interpreted. Clearly, at least in these cases, relevance theory, which claims 
that relevance is determined solely by how easily readers comprehend stated information, is inconsistent with reality.

\section{Conclusions}

As Mey and Talbot (1988) state, relevance theory is an a-contextual notion that denies the essential connection between language and communication. The substantive relevance of a statement cannot be determined by the readers' cognitive abilities, but must instead depend on how well it contributes to, and fits in with, the stated topic, the purpose of the communication, and the communicative needs of the document's readers. We can often make non-relevant statements relevant by changing these metafunctional aspects of a communication - and vice versa of course.

Although occasionally some types of information are essential at certain points in a text (and therefore anything else is irrelevant), writers and speakers often have many items of information to choose from when continuing their discussions. That choice is usually based on the writer's perception of what is, for readers, the most useful or interesting information compatible with the text at that point in the communication. Where space is limited (as it usually is), the choice is more a matter of including information that is more relevant than other information. A cline of most relevant to irrelevant applied to available material is a useful basis for that decision, but we must expect different writers to make different decisions in selecting information for any given topic. In general terms, summary writing should be based on the concept of the relative relevance of competing types of information.

Relevance applies at all levels of a document: from sections or chapters of large documents, through sentences at paragraph level, to items of information within the sentence. It also applies to all aspects of a communication, including prefatory and appended material, illustrations, and tables. We must, however, distinguish it from verbosity and its counterpart, conciseness. Verbosity is the inefficient use of verbiage to express something assumed to be relevant in the first place, whereas conciseness means making the decision that something is irrelevant and totally removing it from the text. The two principles meet when information that has low relevance may nevertheless be included in very brief, or summary, form.

Finally, we need to recognize different types of relevance: those dealing with emphasis, attracting readers, procedural guidance, legal situations, and interpersonal needs and desires. This last set includes a vast array of possible motives, including politeness strategies and the often unexpressed aims of establishing and maintaining personal relations. There is very little interpersonal communication (as defined by Thompson) in formal technical writing, although it does play an important role in communications to the general public and in many administrative and business 
documents and presentations.

Of all the disciplines, professional communication should be more concerned with the practical applications of a theory of relevance than any other. We have always stressed the need to define the audience and purpose for all professional documents and presentations, and we are all keenly aware of the effects these have on the effectiveness of the communication. Yet so far the advice we have been able to offer to students has been little more than platitudes, without a sound basis or framework of understanding.

Further theoretical and empirical work needs to be done to build on the concepts discussed here and to firmly establish a relevance theory that is consistent with actual language use. Once we have such a theoretical framework in place, we will be in a position to use it as a clear basis for teaching one of the most important aspects of professional writing.

\section{References}

Brown, Penelope \& Levinson, Stephen P. (1978). Questions and Politeness. In Esther N.Goody (Ed.), Strategies in Social Interaction. Cambridge: University Press.

__ (1987). Politeness: Some Universals in Language Use. Cambridge: University Press.

Bruce, Bertram (1981). A Social Interaction Model of Reading. Discourse Processes, 4, 273-311.

Chafe, Wallace L. (1974). Language and Consciousness. Language, 50, 111-33.

Clark, Herbert H. (1987a). Relevance to What? Journal of Behavioral and Brain Sciences, 10(4), 714-5.

—_ (1987b). Four Dimensions in Language Use. In M.B.Papi \& Jef Verschueren (Eds.), The Pragmatic Perspective: Proceedings of the 1985 International Pragmatics Conference. Amsterdam: John Benjamins.

Clark, Herbert H. \& Haviland, Susan E. (1977). Comprehension and the GivenNew Contract. In: Roy O.Freedle (Ed.), Discourse Production and Comprehension, Vol. 1: Advances in Discourse Processes (1-40). Norwood, New Jersey: Ablex.

Crawford, Shaney (1995). Writing Errors for Engineering Students: A Diagnostic Analysis. Technostyle, 12(2), 77-85. 
Crystal, David \& Davy, Derek (1969). Investigating English Style. London: Longman.

Dahl, Ötto (1976). What is New Information? In Nils Enkvist \& V.Kanahan (Eds.), Reports on Text Linguistics Approaches to Word Order. Göteborg, Sweden: University of Göteborg.

Daneš, František (1974). Functional Sentence Perspective and the Organization of Text. In František Daneš (Ed.), 106-28.

Daneš, František (Ed.) (1974). Papers on Functional Sentence Perspective. The Hague: Mouton.

Dascal, Marcelo (1977). Conversational Relevance. Journal of Pragmatics, 1, 309-28.

Edmondson, Willis J. (1981). Spoken Discourse: A Model for Analysis. London: Longman.

Eggins, Suzanne and Diana Slade (1997). Analysing Casual Conversation. London: Cassell.

Firbas, Jan (1974). Some Aspects of the Czechoslovak Approach to Problems of Functional Sentence Perspective. In František Daneš (Ed.), 11-37.

Frick, R.W. (1992). Interestingness. British Journal of Psychology, 83(1), 113-28.

Goffman, Erving (1974). Frame Analysis: An Essay on the Organization of Experience. London: Harper and Row.

Gorayska, Barbara \& Lindsay, Roger (1993). The Roots of Relevance. Journal of Pragmatics, 19, 301-23.

- (1995). Not Really a Reply - More Like an Echo: Reply to Steve Nicholle. Journal of Pragmatics, 23, 683-6.

Govier, Trudy (1987). Problems in Argument Analysis and Evaluation. Dordrecht, Holland: Foris Publications.

Grice, H. Paul (1975). Logic and Conversation. In Peter Cole (Ed.), Syntax and Semantics, Vol. 3, Speech Acts (41-58). New York: Academic Press.

Halliday, Michael A.K. (1970). Language Structure and Language Function. In John Lyons (Ed.), New Horizons in Linguistics (140-65). Harmondsworth, Middlesex, England: Pelican. 
Hasan, Ruquaiya (1985). The Structure of a Text. In Michael A.K.Halliday \& Ruquaiya Hasan (Eds.), Language Context and Text: Aspects of Language in a Social-semiotic Perspective. Geelong, Victoria, Australia: Deakin University Press [Oxford University Press, 1989].

Jordan, Michael P. (1984). Fundamentals of Technical Description. Malabar, FLA: Krieger.

— (1990). The Reader Over Your Shoulder: Some Linguistic Background. Technostyle, 9(1), 1-14.

- (1996). The Language of Technical Communication. Kingston, Ontario, Canada: Quarry Press.

- (1998a). The Power of Negation: Text, Context and Relevance. Journal of Pragmatics, 29, 705-52.

_ (1998b). Basic Functional Literacy for Engineering Students: Towards a Linguistic Definition. Technostyle, 14(1), 41-76.

Jucker, Andreas H. (1988). The Discourse Marker "Well": A Relevance-Theoretical Account. Journal of Pragmatics, 19, 435-52.

(1994). Irrelevant Repetitions: A Challenge to Relevance Theory. In Andreas Fischer (Ed.), Repetition: Swiss Papers in English Language and Literature, (748-60). Tübingen: Gunter Narr Verlag.

Lay, Mary M., Wahlstrom, Billie J., Doherty-Farina, S., Duin, Ann H., Burgus Little, S., Rude, Carolyn D., Selfe, Cynthia L., \& Selzer, J. (1995). Technical Communication. Chicago: Irwin.

Martin, Jim R. (1992). English Text: System and Structure. Amsterdam: John Benjamins.

Mey, Jacob L. \& Talbot, Mary (1988). Computation and the Soul. Journal of Pragmatics, 12, 743-89.

Nicolle, Steve (1995). In Defence of Relevance Theory: A Belated Reply to Gorayska and Lindsay, and Jucker. Journal of Pragmatics, 23, 677-81.

Parker, Frank \& Riley, Katherine(1994). Linguistics for Non-linguists, 2 ed., Boston: Allyn and Bacon.

Pike, Kenneth L. (1982). Linguistic Concepts: An Introduction to Tagmemics. Lincoln: University of Nebraska Press. 
Prince, Ellen F. (1981). Toward a Taxonomy of Given-New Information. In Peter Cole (Ed.), Radical Pragmatics (223-57). New York: Academic Press.

Ranous, Charles A. (1964). Communication for Engineers. Boston: Allyn and Bacon.

Riley, Katherine (1993). Telling More about the Truth: Implicature, Speech Acts and Ethics in Professional Communication. Journal of Business Ethics, 12, 179-96.

Sanders, Robert E. (1980). A Theory of the Relationship between Language and Cognition. Communication and Cognition, 13, 77-95.

- (1987). Cognitive Foundations of Calculated Speech: Controlling Understandings in Conversation and Persuasion. Albany, New York: State University of New York Press.

Sperber, Dan \& Wilson, Dierdre (1982). Mutual Knowledge and Relevance in Theories of Comprehension. In Neil V. Smith (Ed.), Mutual Knowledge (6185). London: Academic Press.

_- (1986). Relevance: Communication and Cognition. Oxford: Basil Blackwell.

- (1987). Précis of Relevance: Communication and Cognition. Behavioural and Brain Sciences, 10, 695-754.

Thompson, Geoff (1996). Introducing Functional Grammar. London: Arnold.

van Dijk, Teun A. (1980). Macrostructures: An Interdisciplinary Study of Global Structures in Discourse Interaction and Cognition. Hillsdale, New Jersey: Lawrence Erlbaum.

Walton, Douglas N. (1996). Argument Structure: A Pragmatic Theory. Toronto, Ontario: University of Toronto Press.

Wilks, Yorick (1986). Relevance and Beliefs. In Terry Myers, Keith Brown \& Brendan McGonigle (Eds.), Reasoning and Discourse Processes. New York: Academic Press.

- (1987). Relevance Must be to Someone. Journal of Behavioral Science, 10, 735-6.

Winter, Eugene O.O. (1976). Fundamentals of Information Structure, mimeo, Hatfield, Hertfordshire, England: The Hatfield Polytechnic (now Hertfordshire University), School of Humanities. 
Open Peer Commentary [about relevance theory] and Authors' Responses, Journal of Behavioral and Brain Sciences, 10 (1987), 697-754.

\section{Appendix: Use of Autosummary Facilities}

Word 97 includes an "Autosummarize" facility in its "Tools" tool bar, and it is interesting to note how well this system corresponds to users' intuitions about relevance for some of the examples cited in this discussion. By using the Autosummarize box, we can gradually increase the percentage summary requested and observe the priorities of relevance given by the computer. According to the program, statements included at low summary percentages have high relevance, and those included at high summary percentages have low relevance.

For Example 10, the computer did surprisingly well. With increasing percentage, it first selected the title and first sentence as an inseparable whole, then added sentences 4,3 and 5, leaving sentence 2 as the "least relevant" sentence in the text. This corresponds to my own judgment, although my students rated sentence 5 as less relevant than sentence 2 . The priority order given by the computer for this example is certainly defensible - and thus a useful one on which to base a writer's own priorities. Only whole sentences were added, however, and this is an obvious defect as frequently parts of sentences have different relevance levels than other parts of the same sentence.

For Example 1, the relevance priorities given at different summary levels by the computer were:

$15 \%$ Enjoy walking, dancing, swimming, dining out, country music.

$30 \% \quad 30$-year-old female student $155 \mathrm{lb}, 5$ '3," outgoing and lovable.

$75 \%$ Seeks a male, $35-40$, no children and like to have fun.

$90 \%$ I'LL CALL YOU BACK!

95\% A smoker, $\mathrm{n} / \mathrm{d}$.

Length was not the criterion, as I found by deleting everything in the first selected sentence but the word enjoy. It was still selected as most relevant! Changing the order of the information did not affect the computer's decision. While we may not completely agree with the relevance priorities of the computer, it did at least provide a sensible response to the question of relevance. The second and third lines raised the question of different levels of relevance within a single sentence; surely some of these items have much greater relevance than others.

For some examples, however, the computer did less well. It included the final (irrelevant) sentence of Example 3 at $45 \%$ and the irrelevant sentence of Example 7 also at $45 \%$. When the clearly irrelevant sentence "Traffic in Norway has increased 
$20 \%$ over the last five years." was added to Example 4, the autosummarizer included it at the 50\% level, whereas it should have been added last (95-100\%).

This very small study of the Autosummarizer facility is obviously inconclusive, but it does indicate that the system may have some usefulness in providing an indication of relevance in some instances. In others, however, it is clearly inaccurate and misleading. A detailed study of the system and the criteria used should prove rewarding. 